\title{
Treatment outcome and its predictors among patients of acute heart failure at a tertiary care hospital in Ethiopia: a prospective observational study
}

\author{
Mulubirhan Tirfe ${ }^{1}$, Teshome Nedi ${ }^{2}$, Desalew Mekonnen ${ }^{3}$ and Alemseged Beyene Berha ${ }^{2^{*}}$ (D)
}

\begin{abstract}
Background: Acute heart failure is a rapid onset of new or worsening of signs and symptoms of heart failure that requires hospitalization or a visit to the emergency department. The aim of this study was to evaluate treatment outcome and determine factors that predict a poor treatment outcome in acute heart failure patients at a Tertiary Care Hospital in Ethiopia.

Methods: A prospective observational study design was used. Data were collected using a structured questionnaire as a tool. Outcome variables were assessed at the time of discharge from the hospital. Bivariate and multivariate logistic regression analyses were used to determine factors that predict in-hospital mortality. A $p$-value $\leq 0.05$ was considered as statistically significant.

Results: Out of the 169 patients, the median age of patients with acute heart failure was 34 years (IQR $=23$ to 50) and median hospital stay was 4.0 days (IQR $=3.0$ to 6.0). The leading precipitating factor and underlying disease at the time of admission were pneumonia (47.5\%) and chronic rheumatic heart disease (48.5\%), respectively. The inhospital mortality was found to be $17.2 \%$. Smoking (adjusted odds ratio $(A O R)=8.7, p=0.006$ ), diabetes mellitus $(\mathrm{AOR}=10.2, p=0.005)$, pulmonary hypertension $(\mathrm{AOR}=4.3, p=0.016)$, and the presence of adverse drug events $(\mathrm{AOR}=4.2, p=0.003)$ were predictors of in-hospital mortality.
\end{abstract}

Conclusion: High in-hospital mortality was observed among acute heart failure patients admitted to a Tertiary Care Hospital in Ethiopia. Smoking, diabetes mellitus, pulmonary hypertension and the presence of adverse drug events were predictors of in-hospital mortality.

Keywords: Acute heart failure, In-hospital mortality, Predictor of mortality, Ethiopia

\section{Background}

Acute heart failure (AHF) is a rapid onset of new or worsening of signs and symptoms of heart failure (HF) that is associated with elevated plasma levels of natriuretic peptides [1]. AHF syndromes manifestas newonset 'de novo' or recurrence of acute decompensated heart failure (ADHF) requiring emergency treatment and hospitalization $[2,3]$. The incidences of AHF vary in

\footnotetext{
* Correspondence: alembeyene98@gmail.com

${ }^{2}$ Department of Pharmacology and Clinical Pharmacy, School of Pharmacy, College of Health Sciences, Addis Ababa University, Churchill Avenue, P.O. Box 1176, Addis Ababa, Ethiopia

Full list of author information is available at the end of the article
}

the different part of the world. Its increasing incidence is due to an increasing aging, population, complications arising from cardiovascular diseases like acute coronary syndrome (ACS) and increasing prevalence of lifestylerelated risk factors [4]. AHF patients who attended at hospitals in Africa are young and have severe symptoms due to late presentation. Thus, we should address the young people who are affected by the burden of an acute attack of HF. These younger age group had a significant impact on the economy of the society $[5,6]$.

Adherence to medication predicts health outcomes. Failure to adhere to HF medication was associated with poor treatment outcomes [7]. Patients should receive

(c) The Author(s). 2020 Open Access This article is distributed under the terms of the Creative Commons Attribution 4.0 International License (http://creativecommons.org/licenses/by/4.0/), which permits unrestricted use, distribution, and reproduction in any medium, provided you give appropriate credit to the original author(s) and the source, provide a link to the Creative Commons license, and indicate if changes were made. The Creative Commons Public Domain Dedication waiver (http://creativecommons.org/publicdomain/zero/1.0/) applies to the data made available in this article, unless otherwise stated. 
appropriate therapy as early as possible to achieve good treatment outcomes.

Evaluating reasons for hospitalization in AHF is important to give due attention to precipitating factors. The most common precipitating factors are non-compliance to salt restriction, pulmonary infections, arrhythmias and misuse of HF medications [8].The study conducted by Blecker S et.al has shown hospitalized AHF patients didn't receive appropriate therapy [9]. Besides worsening, AHF was common in hospitalized patients and it was associated with higher mortality rates [10]. Therefore, managing AHF patients according to guideline recommendation could reduce patient hospitalization, decrease morbidity and mortality.

Limited studies and literatures are available in Africa and other developing countries that describe the clinical characteristics, management, and treatment outcome of AHF patients. Therefore, the present study could provide valuable insights to the patient's treatment outcome and predictors of in- hospital mortality among patients hospitalized with AHF in Ethiopia.

\section{Methods}

\section{Study design and setting}

A hospital-based prospective observational study design was used. The study was conducted from May 15 to September 12, 2017, through a structured data abstraction tool. This study was conducted at Tikur Anbessa Specialized Hospital, Addis Ababa, Ethiopia. Tikur Anbessa Specialized Hospital is the largest referral hospital in the country. It has over 700 beds, and serves about 310,000 and 32,000 patients per year in its outpatient and inpatient departments, respectively. The emergency department (ED) also provides services to about 29,000 patients per year and on average 50 patients per day [11]. All patients admitted to the hospital with a diagnosis of AHF during the study period were recruited.

\section{Data collection}

The data abstraction tool included socio-demographic characteristics, clinical features, laboratory data, precipitating factors, underlying diseases, co-morbidity, imaging studies, treatments given and hospital stay. The treatment outcome was assessed at the time of discharge from the hospital.

\section{Ethical clearance}

Ethical clearance was obtained from the Ethical Review Committee of School of Pharmacy, College of Health Sciences, Addis Ababa University (Ref. no ERB/SOP/20/ 09/2017). Permission was also obtained from the Department of Internal Medicine, School of Medicine, College of Health Sciences, Addis Ababa University. Informed oral consent was obtained from patients and for those whose age was $<18$ years consent as well as assent was obtained from guardians.

\section{Data analysis}

Findings were presented as mean \pm (SD) for normal distributed, otherwise median (inter-quartile range) for non-normal distributed variables. Categorical variables were reported as percentages and frequency Tables. A chi-square test was used for categorical variables. Bivariate and multivariate logistic regression was used to analyze factors that predict poor treatment outcomes, and variables whose $p$-values $<0.2$ in the univariate analysis were included in the multivariate model. The level of significance was chosen at $\mathrm{p}$-value $\leq 0.05$ and results were reported as $95 \%$ confidence intervals. For all statistical analysis Statistical Package for Social Sciences (SPSS version 20) was used.

\section{Data quality assurance}

One day training was given for data collectors on the importance, objectives, and method of data collection. There was on-going supervision by the principal investigator. A pre-test was done on 11 consecutive patients to assure clarity, avoidance of ambiguity, comprehensiveness and content uniformity.

\section{Operational definitions}

Acute heart failure: - sign and symptoms of new-onset of $\mathrm{HF}$ and/or decompensation or worsening of chronic stable HF; Adverse drug events: - any injury occurring during the patient's drug therapy and resulting either from appropriate care or unsuitable or suboptimal care; Evidence-based guidelines: - consensus approaches for handling recurring health management problems aimed at reducing practice variability and improving health outcomes. Smoker:- those who are current smokers and had a history of smoking in the last 1 month only; Inappropriate dose:- defined according to European Society of Cardiology management of AHF in the first $48 \mathrm{~h}$ used as a reference [1].

\section{Results \\ Socio-demographic characteristics}

From a total of 181 AHF patients admitted to the emergency and medical wards of Tikur Anbessa Specialized Hospital between May 15 to September 12, 2017; 12 patients declined to participate and a total of 169 patients who were diagnosed with AHF were included in the study. Of these, 120 (71.0\%) patients are urban residents; 104 (61.5\%) were married; and $92(54.4 \%)$ of the patients were females. Of the 169 patients, nine (5.3\%) were smokers and $16(9.5 \%)$ of the patients were readmitted during the study period (Table 1). 
Table 1 Socio-demographic characteristics of acute heart failure patients admitted to Tikur Anbessa Specialized Hospital, Ethiopia between May 15 to September 12, $2017(n=169)$

\begin{tabular}{lll}
\hline Variable & Description & Frequency (\%) \\
\hline Residence & Urban & $120(71.0)$ \\
Education & Rural & $49(29.0)$ \\
& No formal education & $30(17.8)$ \\
& Primary school & $71(42.0)$ \\
& Secondary school & $30(17.8)$ \\
Marital status & Higher education & $38(22.5)$ \\
& Married & $104(61.5)$ \\
& Single & $54(32.0)$ \\
Gender & Divorced & $7(4.2)$ \\
Smoking & Widowed & $4(2.4)$ \\
& Female & $92(54.4)$ \\
Alcohol intake & Male & $77(45.6)$ \\
& Yes & $9(5.3)$ \\
Readmission & No & $160(94.7)$ \\
& Yes & $15(8.9)$ \\
& No & $154(91.1)$ \\
& Yes & $16(9.5)$ \\
& No & $153(90.5)$ \\
\hline
\end{tabular}

As shown in Table 2, the median age of patients was 34.0 years (interquartile range $(\mathrm{IQR})=23$ to 50 ). The median time required to reach the health institutions was $1: 00 \mathrm{~h}$ (IQR $=0: 30$ to $2: 00)$. The median hospital stay of patients was 4.0 days (IQR $=3.0$ to 6.0 ).

\section{Clinical characteristics}

Out of the total 169 AHF patients, 74 (44.0\%) of them had a documented echocardiographic measurement with the result of $55(74.3 \%)$ had preserved ejection fraction and $15(20.3 \%)$ had reduced ejection fraction. In accordance with Framingham's heart failure criteria, 99 (59.0\%) had a combination of two or more Framingham major criteria at admission. Among these most frequently observed combinations of major criteria were neck vein distension and paroxysmal nocturnal dyspnea, followed by neck vein distension and $\mathrm{S}_{3}$ gallop (Table 3 ).

Serum potassium was determined during presentation for 116 patients with mean $\pm(\mathrm{SD})$ value of $4.1 \pm 0.9$ $\mathrm{mEq} / \mathrm{L}$; of these, $32(27.6 \%)$ had serum potassium concentration $<3.55 \mathrm{mEq} / \mathrm{L}$, and $7(6.0 \%)$ had serum potassium concentration $>5.55 \mathrm{mEq} / \mathrm{L}$. The mean $\pm(\mathrm{SD})$ value of hemoglobin for 158 patients at admission was $12.8 \pm 3.0 \mathrm{~g} / \mathrm{dL}$, among those $24(15.2 \%)$ had clinically significant anemia (hemoglobin $<10 \mathrm{~g} / \mathrm{dL}$ ).

Blood urea nitrogen and serum creatinine measurement was found for 62 and 145 of the patients, respectively; median value of BUN was $70.6 \mathrm{mg} / \mathrm{dL}(\mathrm{IQR}=49.2$, $127.3)$ and $47(75.8 \%)$ had elevated BUN level $(\geq 43 \mathrm{mg} /$ $\mathrm{dL})$. Elevated serum creatinine value $(\geq 1.2 \mathrm{mg} / \mathrm{dL})$ was found in $58(40.0 \%)$ of the patients at admission.

Data for estimated glomerular filtration rate (GFR) was found for 145 patients with mean $\pm(\mathrm{SD})$ value of $74.2 \pm 33.0 \mathrm{~mL} / \mathrm{min} / 1.73 \mathrm{~m}^{2}$. Of the 145 patients based on Modification of Diet in Renal Disease (MDRD) derived formula 12 (8.3\%) patients had $\leq 30 \mathrm{~mL} / \mathrm{min} /$ $1.73 \mathrm{~m}^{2}$ value, $30(20.7 \%)$ patients had 30 to $59 \mathrm{~mL} / \mathrm{min} /$ $1.73 \mathrm{~m}^{2}$ and $61(42.1 \%)$ patients had 60 to $89 \mathrm{~mL} / \mathrm{min} /$ $1.73 \mathrm{~m}^{2}$ estimated GFR (See in Table 4).

Findings for chest X-ray, electrocardiogram (ECG) and echocardiography were obtained for 42 (25.0\%), 109 (64.5\%) and $83(49.1 \%)$ patients, respectively. Of the 109 patients who had ECG, atrial fibrillation was detected in $59(54.1 \%)$ of the patients. (See in Table 5).

Factors that precipitate AHF at admission were found for 160 patients, among these the top four precipitating factors were pneumonia 76 (47.5\%), atrial fibrillation 55 (34.4\%), anemia 39 (24.4\%), and drug discontinuation 36 (22.5\%). The three most common underlying diseases found in AHF patients in order of decreasing frequency were chronic rheumatic heart disease (RHD) 82 (48.5\%), degenerative valvular heart disease (VHD) 37 (22.5\%), and congenital heart disease (CHD) 33 (19.5\%). Chronic kidney disease (CKD) 18 (10.7\%) was the most common co-morbid disease followed by pulmonary hypertension 17 (10.1\%) and hypertension 14 (8.3\%) (See in Table 6).

Table 2 Vital signs and ejection fraction of acute heart failure patients admitted to Tikur Anbessa Specialized Hospital, Ethiopia between May 15 to September 12, $2017(n=169)$

\begin{tabular}{|c|c|c|c|c|c|c|c|}
\hline Variables & $\mathrm{N}$ & Frequency (\%) & Mean & SD & Median & Q1 & Q3 \\
\hline Age (years) & 169 & & 37.8 & 17.8 & 34.0 & 23.0 & 50.0 \\
\hline Time required to reach $\mathrm{HI}(\mathrm{hr})$ & 169 & & $1: 17$ & $0: 55$ & $1: 00$ & $0: 30$ & $2: 00$ \\
\hline Hospital stay (days) & 169 & & 7.1 & 10.0 & 4.0 & 3.0 & 6.0 \\
\hline Ejection fraction (\%) & 74 & & 53.8 & 13.7 & 55.0 & 45.8 & 63.3 \\
\hline Preserved EF ( $\geq 50 \%)$ & & $55(74.3)$ & & & & & \\
\hline Reduced EF ( $\leq 40 \%)$ & & $15(20.3)$ & & & & & \\
\hline Mid-range EF (41 to 49\%) & & $4(5.4)$ & & & & & \\
\hline
\end{tabular}

Key: $H$ I health institution, $S D$ standard deviation, Q1. $=25$ th percentile, $Q 3=75$ th percentile 
Table 3 Framingham major criteria of acute heart failure patients admitted to Tikur Anbessa Specialized Hospital, Ethiopia between May 15 to September 12, $2017(n=169)$

\begin{tabular}{|c|c|}
\hline Combination Framingham major criteria & Frequency (\%) \\
\hline Neck vein distension + Paroxysmal nocturnal dyspnea & $30(17.8)$ \\
\hline Neck vein distension $+\mathrm{S}_{3}$ gallop & $12(7.1)$ \\
\hline Neck vein distension + Rales & $10(5.9)$ \\
\hline Paroxysmal nocturnal dyspnea $+S_{3}$ gallop & $10(5.9)$ \\
\hline Neck vein distension + Acute pulmonary edema & $6(3.6)$ \\
\hline Paroxysmal nocturnal dyspnea + Rales & $6(3.6)$ \\
\hline Neck vein distension + Paroxysmal nocturnal dyspnea + Rales & $5(3.0)$ \\
\hline Neck vein distension + Paroxysmal nocturnal dyspnea + Acute pulmonary edema & $4(2.4)$ \\
\hline Paroxysmal nocturnal dyspnea + Acute pulmonary edema & $4(2.4)$ \\
\hline Neck vein distension + Rales $+S_{3}$ gallop & $4(2.4)$ \\
\hline Other combination criteria ${ }^{a}$ & $8(4.8)$ \\
\hline
\end{tabular}

NB: ${ }^{a}\left(\right.$ Neck vein distension + Acute pulmonary edema $+S_{3}$ gallop), (Acute pulmonary edema $+S_{3}$ gallop), (Acute pulmonary edema + Cardiomegally), (Neck vein distension + Paroxysmal nocturnal dyspnea $+S_{3}$ gallop), (Rales $+S_{3}$ gallop), (Acute pulmonary edema + Rales $+S_{3}$ gallop)

Table 4 Laboratory values of acute heart failure patients admitted to Tikur Anbessa Specialized Hospital, Ethiopia between May 15 to September 12, $2017(n=169)$

\begin{tabular}{|c|c|c|c|c|c|c|c|}
\hline Variables & N & Frequency (\%) & Mean & SD & Median & Q1 & Q3 \\
\hline Serum sodium (mEq/L) & 120 & & 135.8 & 10.1 & 136.5 & 130.5 & 143.3 \\
\hline Serum sodium $\geq 135 \mathrm{mEq} / \mathrm{L}$ & & $72(60.0)$ & & & & & \\
\hline Serum sodium $<135 \mathrm{mEq} / \mathrm{L}$ & & $48(40.0)$ & & & & & \\
\hline Serum potassium (mEq/L) & 116 & & 4.1 & 0.9 & 4.0 & 3.47 & 4.53 \\
\hline Normal & & $77(66.4)$ & & & & & \\
\hline Hypokalemia (< 3.55 mEq/L) & & $32(27.6)$ & & & & & \\
\hline Hyperkalemia (> 5.55 mEq/L) & & $7(6.0)$ & & & & & \\
\hline Hemoglobin $(\mathrm{g} / \mathrm{dL})^{\mathrm{a}}$ & 158 & & 12.8 & 3.0 & 12.8 & 10.8 & 14.8 \\
\hline Hemoglobin $\geq 12 \mathrm{~g} / \mathrm{dL}$ & & $98(62.0)$ & & & & & \\
\hline Hemoglobin $<12 \mathrm{~g} / \mathrm{dL}$ & & $60(38.0)$ & & & & & \\
\hline Hemoglobin $<10 \mathrm{~g} / \mathrm{dL}$ & & $24(15.2)$ & & & & & \\
\hline Serum creatinine (mg/dL) & 145 & & 1.6 & 1.8 & 1.2 & 1.0 & 1.5 \\
\hline Normal serum creatinine $\leq 1.2$ & & $87(60.0)$ & & & & & \\
\hline Elevated serum creatinine $>1.2$ & & $58(40.0)$ & & & & & \\
\hline Blood urea nitrogen (mg/dL) & 62 & & 110.5 & 95.3 & 70.6 & 49.2 & 127.3 \\
\hline Less than $43 \mathrm{mg} / \mathrm{dL}$ & & $15(24.2)$ & & & & & \\
\hline Elevated $\geq 43 \mathrm{mg} / \mathrm{dL}$ & & $47(75.8)$ & & & & & \\
\hline $\operatorname{eGFR}\left(\mathrm{mL} / \mathrm{min} / 1.73 \mathrm{~m}^{2}\right)$ & 145 & & 74.2 & 33.0 & 74.0 & 55.0 & 92.0 \\
\hline$\leq 14$ & & $8(5.5)$ & & & & & \\
\hline 15 to 29 & & $4(2.8)$ & & & & & \\
\hline 30 to 59 & & $30(20.7)$ & & & & & \\
\hline 60 to 89 & & $61(42.1)$ & & & & & \\
\hline$\geq 90$ & & $42(29.0)$ & & & & & \\
\hline
\end{tabular}

NB: ${ }^{a}$ Measurement taken after patient was stabilized Key: eGFR = estimated glomerular filtration rate, $\mathrm{SD}=$ standard deviation; $\mathrm{Q} 1=25$ th percentile, $\mathrm{Q} 3=75$ th percentile 
Table 5 Imaging findings of acute heart failure patients admitted to Tikur Anbessa Specialized Hospital, Ethiopia between May 15 to September 12, $2017(n=169)$

\begin{tabular}{|c|c|c|}
\hline Imaging & Finding & Frequency (\%) \\
\hline \multirow[t]{4}{*}{ Chest X-ray $(N=42)$} & Pulmonary edema & $27(64.3)$ \\
\hline & Pleural effusion & $12(28.6)$ \\
\hline & Pneumonia & $6(14.3)$ \\
\hline & Normal & $3(7.1)$ \\
\hline \multirow[t]{4}{*}{ Electrocardiogram $(N=109)$} & Atrial fibrillation & $59(54.1)$ \\
\hline & Sinus tachycardia & $37(33.9)$ \\
\hline & Sinus rhythm & $12(11.0)$ \\
\hline & Bradycardia & $5(4.6)$ \\
\hline \multirow[t]{6}{*}{ Echocardiography $(N=83)$} & Chronic rheumatic heart disease & $67(80.7)$ \\
\hline & Pulmonary hypertension & $55(66.3)$ \\
\hline & Hypertensive heart disease / LVH & $11(13.3)$ \\
\hline & Ischemic heart disease & $8(9.6)$ \\
\hline & Pericardial effusion & $3(3.6)$ \\
\hline & Others (normal, degenerative heart disease) & $4(2.4)$ \\
\hline
\end{tabular}

Key: LVH Left ventricular hypertrophy

\section{Treatment outcome and its predictors}

Out of the total 169 patients, $140(82.8 \%)$ patients had clinically improved and $29(17.2 \%)$ patients died while they were at the hospital. Adverse drug events were found in $47(27.8 \%)$ of the patients and inappropriate drug dose was prescribed to $5(3.0 \%)$ patients (Table 7 ).

In the chi-squared test, smoking, pulmonary hypertension, diabetes mellitus and presence of adverse drug events were independently associated with in-hospital mortality of AHF (See in Table 8).

In multivariate logistic regression analysis smoking, diabetes mellitus, pulmonary hypertension and presence of adverse drug events had a statistically significant association with in-hospital mortality (See in Table 9).

\section{Discussion}

AHF patients presenting to a tertiary care hospital were young and had pneumonia as a major precipitating factor. The leading underlying disease was chronic rheumatic heart disease (RHD) and major co-morbid disease was chronic kidney disease (CKD). 17.2\% of the patients had died in the hospital.

More than half of the AHF patients in this study were female $92(54.4 \%)$ which was comparable to registry studies in sub-Saharan Africa Survey on Heart Failure (50.8\%), the 5 year retrospective cohort study of African patients admitted with heart failure (54.4\%), Acute Decompensated Heart Failure Registry (ADHERE) (52.0\%) and the Organized Program to Initiate Lifesaving Treatment in Hospitalized Patients with Heart Failure (OPTIMIZE-HF) (52.0\%) [5, 12-14]. However, the European registries Euro Heart Failure Survey II (EHFS II) (39.0\%), Heart Failure Pilot Study (ESC-HF pilot)
(47.0\%) and the Acute Heart Failure Global Registry of Standard Treatment (ALARM-HF) (37.6) studies females had lower frequency as compared to males [15-18].

Patients admitted in this study were young (median = 34 years). This was contrary to registries in ADHERE $($ mean $=72.4)$, OPTIMIZE-HF $($ mean $=73)$, OFICA $($ median $=79.0$ ), Korean Acute Heart Failure Registry (KorAHF) $($ mean $=68.5)$ and the sub-Saharan Africa Survey of Heart Failure cohort $($ mean $=52.3)[5,12,15,19,20]$. Reason for younger age admission could be related to the high prevalence of RHD in Ethiopia [21]. Similarly, in the study by Abdissa and his colleagues the peak age of diagnosis with VHD among Ethiopian patients was in their third decade mean $\pm(\mathrm{SD})=24.4 \pm 9.7$ years [22] AHF in Tikur Anbessa Specialized Hospital pediatric ward was primarily due to RHD [21]. Supported by Soweto study 2006/07 South Africa, RHD was peaked predominantly in the third decade of life [23].

In the present study leading precipitating factors were pneumonia, atrial fibrillation, anemia and drug discontinuation. Similar to our study, in the OPTIMIZE-HF registry study pneumonia, ischemia/acute coronary syndrome and arrhythmia were leading precipitating factors [13].. This was also comparable with the ALARM-HF registry study where arrhythmia, infection and noncompliance to medication were the most frequent precipitating factors [18].

In the current study drug discontinuation as precipitating factor was reported in $22.5 \%$ of the patients, and almost 101 (59.8\%) patients had a primary school and no formal education. Adherence to heart failure medication regimens could be influenced by inadequate support, lack of education and illiteracy. In addition to optimal 
Table 6 Precipitating factors, underlying and co-morbid diseases of acute heart failure patients admitted to Tikur Anbessa Specialized Hospital, Ethiopia between May 15 to September 12, $2017(n=169)$

\begin{tabular}{|c|c|}
\hline Factors / diseases & Frequency (\%) \\
\hline \multicolumn{2}{|l|}{ Precipitating factors $(n=160)$} \\
\hline Pneumonia & $76(47.5)$ \\
\hline Atrial fibrillation & $55(34.4)$ \\
\hline Anemia & $39(24.4)$ \\
\hline Drug discontinuation & $36(22.5)$ \\
\hline Infective endocarditis & $7(4.4)$ \\
\hline Acute coronary syndrome & $6(3.8)$ \\
\hline Others (Pregnancy, uncontrolled hypertension) & $6(3.8)$ \\
\hline \multicolumn{2}{|l|}{ Underlying $(n=169)$} \\
\hline Chronic rheumatic heart disease & $82(48.5)$ \\
\hline Degenerative heart disease & $38(22.5)$ \\
\hline Congenital heart disease & $33(19.5)$ \\
\hline Hypertensive heart disease & $17(10.1)$ \\
\hline Ischemic heart disease & $17(10.1)$ \\
\hline Cor pulmonale & $14(8.3)$ \\
\hline Dilated cardiomyopathy & $14(8.3)$ \\
\hline \multicolumn{2}{|l|}{ Co-morbid $(n=169)$} \\
\hline Chronic kidney disease & $18(10.7)$ \\
\hline Pulmonary hypertension & $17(10.1)$ \\
\hline Hypertension & $14(8.3)$ \\
\hline Diabetes mellitus & $8(4.7)$ \\
\hline Coronary artery disease & $8(4.7)$ \\
\hline Asthma & $8(4.7)$ \\
\hline Chronic obstructive pulmonary disease & $7(4.1)$ \\
\hline Tuberculosis & $6(3.6)$ \\
\hline HIV/AIDS & $4(2.4)$ \\
\hline Others $^{a}$ & $8(4.7)$ \\
\hline
\end{tabular}

NB: ${ }^{a}$ Cancer, hyperthyriodism, pericardial effusion, stroke

Table 7 Treatment outcome and drug use assessment of acute heart failure patients admitted to Tikur Anbessa Specialized Hospital, Ethiopia between May 15 to September 12, $2017(n=169)$

\begin{tabular}{ll}
\hline Treatment outcome and drug use assessment & Frequency (\%) \\
\hline Clinically improved & $140(82.8)$ \\
In-hospital mortality & $29(17.2)$ \\
Adverse drug events & $47(27.8)$ \\
Electrolyte imbalance & $39(23.1)$ \\
Digoxin and warfarin toxicity & $8(4.7)$ \\
Inappropriate drug dose $^{\text {Others }}{ }^{\text {a }}$ & $5(3.0)$ \\
\hline
\end{tabular}

NB: alnappropriate drug administered, inappropriate drug combination, prescribed drug not available pharmacologic treatment patient education on medication adherence had improved outcomes, [2]. Thus, clinical pharmacists had key role in medication adherence of heart failure patients as demonstrated by the Pharmacist in Heart Failure Assessment Recommendation and Monitoring (PHARM) study. Interventions made by clinical pharmacists lowered readmission/death by more than $50.0 \%$ through closer follow-up [24].

The leading underlying disease found was chronic RHD this was supported by different studies. In developing countries heart failure was primarily due to VHD whereas developed countries it was mainly due to ischemic disease [25]. Studies in the African population showed RHD was the commonest diagnosis among patients with cardiovascular diseases. The study at Jimma Specialized Hospital in Ethiopia showed RHD was the commonest diagnosis among patients presented to the cardiac clinic [26]. In Tikur Anbessa Specialized Hospital, the VHD was the commonest diagnosis among patients with cardiovascular diseases [22]. This was also similar to studies done in sub-Saharan Africa where cardiomyopathy and RHD accounted for almost half of all cases presented to hospitals [27-29]. However, this was different from THESUS-HF study where hypertensive and ischemic heart disease(IHD) were the primary causes [5].

This study showed that treatment was targeted mainly towards symptom relief, the underlying and/or comorbid disease were most commonly treated by frusemide, spironolactone, digoxin and warfarin. In the current study, warfarin and digoxin had higher consumption rates which were used for the management of VHD and atrial fibrillation $[2,30,31]$.

The present study showed in-hospital mortality of $17.2 \%$ which is comparable with the mortality of THESUS-HF cohort study [5]. This was higher than the study of systematic review and meta-analysis in low and middle income countries that a $2.2 \%$ of hospital admission was AHF with mean in-hospital mortality of $8 \%$ [32].Globally, hospitalized patients had higher mortality (30.6\%) and African patients had the highest adjusted hazard of death (34\%) within 1 year. This variation in mortality might be related to the difference in healthcare infrastructure, quality of care, environmental and genetic factors in different regions of the world [33].

Adverse drug events were a predictor of in-hospital mortality that occurred in $27.8 \%$ of the patients. This study found hypokalemia in $27.6 \%$ and hyperkalemia in $6.0 \%$ of the patients. Use of loop diuretic could lead to hypokalemia and drugs that increase potassium level especially in renal dysfunction such as a combination of angiotensin converting enzyme inhibitors, potassium chloride and spironolactone could lead to hyperkalemia. Use of non-potassium sparing diuretics was significantly 
Table 8 Chi-square test of variables associated with in-hospital mortality of acute heart failure patients admitted to Tikur Anbessa Specialized Hospital, Ethiopia between May 15 to September 12, 2017 ( $n=169)$

\begin{tabular}{lll}
\hline Variables & Percent poor treatment outcome $(95 \% \mathrm{Cl})$ & $P$ value \\
\hline Adverse drug events(ADR/SE) absent & $12.3 \%(6.4,18.2)$ \\
Adverse drug events(ADR/SE) present & $29.8 \%(16.7,42.9)$ \\
One Framingham major criterion & $13.8 \%(13.4,14.2)$ \\
More than one Framingham major criteria & $22.1 \%(14.1,30.1)$ \\
Diabetes mellitus absent & $15.6 \%(10.4,21.8)$ \\
Diabetes mellitus present & $50.0 \%(15.3,84.7)$ \\
Pulmonary hypertension absent & $15.1 \%(9.4,20.8)$ \\
Pulmonary hypertension present & $41.2 \%(17.9,64.5)$ \\
Non-smokers & $15.6 \%(9.9,21.3)$ \\
Smokers & $44.4 \%(11.9,76.9)$ & 0.041 \\
\hline
\end{tabular}

Key: $A D R / S E$ Adverse drug reaction/side effect, $\mathrm{Cl}$ confidence interval

associated with increased risk of arrhythmic death. Diuretic-induced electrolyte disturbance might ultimately resulted in fatal arrhythmia in patients using nonpotassium sparing diuretics [34].

In our study AHF patients with pulmonary hypertension had higher mortality. Similarly, Lowe and colleagues showed patients with pulmonary hypertension had twofold risk of mortality [35]. The increased mortality in patients with pulmonary hypertension might be due to an aggressive afterload reduction with vasodilator or diuretics treatment that could finally end up in cardiovascular collapse as these patients could not increase their forward blood through flow restricted valve [36].

Table 9 Univariate and multivariate logistic regression analysis of acute heart failure patients admitted to Tikur Anbessa Specialized Hospital, Ethiopia between May 15 to September 12, $2017(n=169)$

\begin{tabular}{|c|c|c|c|c|c|c|}
\hline \multirow[t]{2}{*}{ Variables } & \multicolumn{2}{|c|}{ Univariate } & \multirow[t]{2}{*}{$P$ value } & \multicolumn{2}{|c|}{ Multivariate } & \multirow[t]{2}{*}{$P$ value } \\
\hline & $\mathrm{OR}$ & $95 \% \mathrm{Cl}$ & & $\mathrm{AOR}$ & $95 \% \mathrm{Cl}$ & \\
\hline \multicolumn{7}{|l|}{ Socio-demographic } \\
\hline Age $^{b}$ & 1.0 & $0.98,1.00$ & 0.89 & & & \\
\hline Alcohol intake ${ }^{a}$ & 1.9 & $0.55,6.40$ & 0.30 & & & \\
\hline Salt intake ${ }^{a}$ & 0.7 & $0.23,1.80$ & 0.40 & & & \\
\hline Smoking ${ }^{a}$ & 4.3 & $1.10,17.20$ & 0.038 & 8.72 & $1.84,41.30$ & 0.006 \\
\hline \multicolumn{7}{|l|}{ Diseases } \\
\hline Atrial fibrillation ${ }^{a}$ & 1.6 & $0.67,3.70$ & 0.30 & & & \\
\hline Cancer $^{a}$ & 10.3 & $0.9,117.6$ & 0.06 & & & \\
\hline Chronic kidney disease ${ }^{a}$ & 1.4 & $0.40,4.70$ & 0.56 & & & \\
\hline Chronic rheumatic heart disease $^{a}$ & 1.9 & $0.86,4.40$ & 0.11 & & & \\
\hline Diabetes mellitus ${ }^{a}$ & 5.4 & $1.30,23.20$ & 0.022 & 10.18 & $2.04,50.85$ & 0.005 \\
\hline Hypertension $^{a}$ & 1.4 & $0.40,5.20$ & 0.67 & & & \\
\hline Hypertensive heart disease ${ }^{a}$ & 2.2 & $0.70,6.90$ & 0.17 & & & \\
\hline Pneumonia ${ }^{a}$ & 1.3 & $0.60,3.00$ & 0.48 & & & \\
\hline Pulmonary hypertension ${ }^{a}$ & 4.1 & $1.40,12.00$ & 0.009 & 4.33 & $1.31,14.25$ & 0.016 \\
\hline \multicolumn{7}{|l|}{ Other } \\
\hline Adverse drug events ${ }^{a}$ & 3.0 & $1.30,6.90$ & 0.009 & 4.23 & $1.62,11.02$ & 0.003 \\
\hline Echocardiography finding* & 3.2 & $0.66,15.50$ & 0.15 & & & \\
\hline Framingham major criteria** & 2.7 & $1.00,6.90$ & 0.047 & 2.89 & $0.98,8.50$ & 0.054 \\
\hline
\end{tabular}

Key: $A O R$ adjusted odds ratio, $\mathrm{Cl}$ confidence interval

NB: $\left(^{*}\right)$ coded $1=$ one major criteria, $2=$ two or more major criteria, $(* *)$ coded $1=$ one finding, $2=$ more than one finding; (a) coded $0=$ no, $1=$ yes; $(b)$ for 1 unit increase; serum $\mathrm{Na}$ coded $1>135,2<135$; systolic blood pressure = coded $1 \geq 115,2<115$; serum creatinine coded $1 \leq 1.2$ and $2>1.2$ 
Patients with heart failure and preserved ( $\geq 50 \%)$ ejection fraction have multiple co-morbidities including diabetes mellitus, atherosclerosis, renal dysfunction, chronic obstructive lung disease, and anemia. The presence of those co-morbidities were associated with increased allcause mortality among patients [14].The co-morbidities of heart failure patients (preserved EF) were significantly associated with unique clinical, structural, functional and prognostic profiles [37]. The poor clinical outcome of heart failure patients with preserved ejection fraction can not merely be explained by age, sex, presence of comorbidity, low blood pressure and left ventricular remodeling rather than additional involvement of heart failure related mechanisms explained the worse outcome of patients [38]. The variation in cardiac and noncardiac co-morbid conditions, underlying diseases, and clinical profile at presentation, diagnostic and treatment in AHF were heterogeneous across different countries $[5,12,13,15,16,39]$.

There are limited studies on the causes, treatments and outcomes of AHF in Africa. The present study provides information on the clinical characteristics, underlying and co-morbid disease, adverse drug events and treatment outcome and its predictors in AHF in Ethiopia. Ultimately the findings are useful for the policymaker to develop strategies to improve treatment outcomes, quality of care, preventive and diagnostic services of AHF.

\section{Limitations}

The present study has the following limitations. The study was conducted in a single -center with a small sample size. In addition, measurements on biomarkers and laboratory values like BNP, NTproBNP, high sensitive $\mathrm{C}$-reactive protein and uric acid were not available in this study that could be used significantly to predict the outcome of AHF. Besides measurement on cardiac troponin, creatine kinase- $\mathrm{MB}$ and $\mathrm{BUN}$ were not obtained fully.

\section{Conclusion}

High in-hospital mortality rate (17.2\%) was observed among acute heart failure patients admitted to a Tertiary Care Hospital in Ethiopia. Chronic RHD and pneumonia were the leading underlying disease and precipitating factors found in patients admitted with AHF, respectively. Smoking, diabetes mellitus, pulmonary hypertension and the presence of adverse drug events were predictors of poor treatment outcomes. Due attention should be given to co-morbid diseases while patients presented with AHF syndromes. Clinicians should also pay more attention to the management of adverse drug events.

\section{Abbreviations}

ACC/AHA: American College of Cardiology / American Heart Association; ACE: Angiotensin converting enzyme; ACS: Acute coronary syndrome; ADHERE: Acute decompensated heart failure National Registry; ADHF: Acute decompensated heart failure; ADR/SE: Adverse drug event / side effect; AF: Atrial fibrillation; AHF: Acute heart failure; ALARM-HF: Acute heart failure global registry of standard treatment; BNP: B-type natriuretic peptide; BUN: Blood urea nitrogen; CHD: Congenital heart disease; CKD: Chronic kidney disease; DM: Diabetes mellitus; ED: Emergency department; EF: Ejection fraction; EHFS II: EuroHeart failure survey II; ESC: European society of cardiology; ESC-HF pilot: EURObservational research program the heart failure pilot survey; GFR: Glomerular filtration rate; HF: Heart failure; IHD: Ischemic heart disease; KorAHF: Korean acute heart failure registry; MDRD: Modification of diet on renal disease; MI: Myocardial infarction; NTproBNP: N-terminal pro-B-type natriuretic peptide; NYHA: New York heart association; OPTIMIZE-HF: Organized program to initiate lifesaving treatment in hospitalized patients with heart failure; RHD: Rheumatic heart disease; SBP: Systolic blood pressure; THESUS-HF: The sub-Saharan Africa survey of heart failure; VHD: Valvular heart disease

\section{Acknowledgments}

The authors would like to thank all of the patients who gave their time so generously to participate in the research. We also would like to thank the data collectors for their contribution to accomplish the study.

\section{Authors' contributions}

MT designed and conducted the study, analyzed and interpreted results and drafted the manuscript. TN, DM and ABB involved in the design of the study, supervision, drafting the manuscript and its critical review. All authors have given final approval of the version to be published.

\section{Funding}

The study was funded by Addis Ababa University. The funders had no role in the study design, data collection, analysis, interpretation of data, and preparation of the manuscript or decision to publish.

\section{Availability of data and materials}

The datasets used and/or analyzed during the current study are available from the corresponding author on reasonable request.

\section{Ethics approval and consent to participate}

The study was done after ethical approval was obtained from the Ethical Review Committee of School of Pharmacy, College of Health Sciences, Addis Ababa University (Ref. no ERB/SOP/20/09/2017). Informed verbal consent was obtained from patients and for those whose age was $<18$ years consent as well as assent was obtained from guardians. Obtaining only verbal consent was approved by the ethics committee rather than written consent because the research didn't involve any therapeutic interventions and also had a minimal risk to the patients during data collection. Verbal consent was obtained from the patients before starting data collection.

\section{Consent for publication}

Not applicable.

\section{Competing interests}

The authors declare that they have no competing interests.

\section{Author details \\ ${ }^{1}$ Department of Pharmacy, College of Health Sciences and Comprehensive Specialized Hospital, Aksum University, Aksum, Ethiopia. ${ }^{2}$ Department of Pharmacology and Clinical Pharmacy, School of Pharmacy, College of Health Sciences, Addis Ababa University, Churchill Avenue, P.O. Box 1176, Addis Ababa, Ethiopia. ${ }^{3}$ Department of Internal Medicine, School of Medicine, College of Health Sciences, Addis Ababa University, Addis Ababa, Ethiopia.}

Received: 19 October 2018 Accepted: 24 December 2019 Published online: 20 January 2020

\section{References}

1. Mebazaa A, Yilmaz MB, Levy P, Ponikowski P, Peacock WF, Laribi S, Ristic AD, Lambrinou E, Masip J, Riley JP. Recommendations on pre-hospital \& early 
hospital management of acute heart failure: a consensus paper from the heart failure Association of the European Society of cardiology, the European Society of Emergency Medicine and the Society of Academic Emergency Medicine. Eur J Heart Fail. 2015;17(6):544-58.

2. Ponikowski P, Voors AA, Anker SD, Bueno H, Cleland JG, Coats AJ, Falk V, González-Juanatey JR, Harjola V-P, Jankowska EA. 2016 ESC guidelines for the diagnosis and treatment of acute and chronic heart failure: the task force for the diagnosis and treatment of acute and chronic heart failure of the European Society of Cardiology (ESC) developed with the special contribution of the heart failure association (HFA) of the ESC. Eur Heart J. 2016;37(27):2129-200.

3. Gheorghiade M, Pang PS. Acute heart failure syndromes. J Am Coll Cardiol 2009:53(7):557-73.

4. Roger VL, Go AS, Lloyd-Jones DM, Adams RJ, Berry JD, Brown TM, Carnethon MR, Dai S, De Simone G, Ford ES. Heart disease and stroke statistics - 2011 update a report from the American Heart Association. Circulation. 2011;123(4):e18-e209.

5. Damasceno A, Mayosi BM, Sani M, Ogah OS, Mondo C, Ojji D, Dzudie A, Kouam CK, Suliman A, Schrueder N. The causes, treatment, and outcome of acute heart failure in 1006 Africans from 9 countries: results of the sub-Saharan Africa survey of heart failure. Arch Intern Med. 2012;172(18):1386-94.

6. Ogah OS, Stewart S, Falase AO, Akinyemi JO, Adegbite GD, Alabi AA, Ajani AA, Adesina JO, Durodola A, Sliwa K. Contemporary profile of acute heart failure in southern Nigeria: data from the Abeokuta heart failure clinical registry. JACC Heart Fail. 2014;2(3):250-9.

7. Wu JR, DeWalt DA, Baker DW, Schillinger D, Ruo B, Bibbins-Domingo K, Macabasco-O'Connell A, Holmes GM, Broucksou KA, Erman B. A Single-Item Self-Report Medication Adherence Question Predicts Hospitalization and Death in Patients with Heart Failure. J Clin Nurs. 2014;23:2554.

8. Tsuyuki RT, McKelvie RS, Arnold JO, et al. Acute precipitants of congestive heart failure exacerbations. Arch Intern Med. 2001;161(19):2337-42.

9. Blecker S, Agarwal SK, Chang PP, Rosamond WD, Casey DE, KucharskaNewton A, Radford MJ, Coresh J, Katz S. Quality of care for heart failure patients hospitalized for any cause. J Am Coll Cardiol. 2014;63(2):123-30.

10. DeVore AD, Hammill BG, Sharma PP, Qualls LG, Mentz RJ, Johnson KW, Fonarow GC, Curtis LH, Hernandez AF. In-hospital worsening heart failure and associations with mortality, readmission, and healthcare utilization. J Am Heart Assoc. 2014;3(4):e001088.

11. Hospital TAS: Tikur Anbessa Specialized Hospital. http://wwwaaueduet/chs/ tikur-anbessa-specialized-hospital/background-of-tikur-anbessa-hospital. 2019.

12. Adams KF, Fonarow GC, Emerman CL, LeJemtel TH, Costanzo MR, Abraham WT, Berkowitz RL, Galvao M, Horton DP, Committee ASA, et al. Characteristics and outcomes of patients hospitalized for heart failure in the United States: rationale, design, and preliminary observations from the first 100,000 cases in the acute decompensated heart failure National Registry (ADHERE). Am Heart J. 2005;149(2):209-16.

13. Fonarow GC, Abraham WT, Albert NM, Stough WG, Gheorghiade M, Greenberg BH, O'Connor CM, Pieper K, Sun JL, Yancy CW. Factors identified as precipitating hospital admissions for heart failure and clinical outcomes: findings from OPTIMIZE-HF. Arch Intern Med. 2008;168(8):847-54.

14. Bonsu KO, Owusu IK, Buabeng KO, Reidpath DD, Kadirvelu A. Clinical characteristics and prognosis of patients admitted for heart failure: a 5-year retrospective study of African patients. Int J Cardiol. 2017;238:128-35.

15. Gheorghiade M, Abraham WT, Albert NM, Greenberg BH, O'Connor CM, She L, Stough WG, Yancy CW, Young JB, Fonarow GC. Systolic blood pressure at admission, clinical characteristics, and outcomes in patients hospitalized with acute heart failure. JAMA. 2006;296(18):2217-26.

16. Nieminen MS, Brutsaert D, Dickstein K, Drexler H, Follath F, Harjola V-P, Hochadel M, Komajda M, Lassus J, Lopez-Sendon JL. EuroHeart failure survey II (EHFS II): a survey on hospitalized acute heart failure patients: description of population. Eur Heart J. 2006;27(22):2725-36.

17. Maggioni AP, Dahlström U, Filippatos G, Chioncel O, Leiro MC, Drozdz J, Fruhwald F, Gullestad L, Logeart D, Metra M. EURObservational research Programme: the heart failure pilot survey (ESC-HF pilot). Eur J Heart Fail. 2010;12(10):1076-84.

18. Follath F, Yilmaz M, Delgado J, Parissis J, Porcher R, Gayat E, Burrows N, McLean A, Vilas-Boas F, Mebazaa A. Clinical presentation, management and outcomes in the acute heart failure global survey of standard treatment (ALARM-HF). Intensive Care Med. 2011;37(4):619-26.
19. Logeart D, Isnard R, Resche-Rigon M, Seronde MF, Groote P, Jondeau G, Galinier M, Mulak G, Donal E, Delahaye F. Current aspects of the spectrum of acute heart failure syndromes in a real-life setting: the OFICA study. Eur J Heart Fail. 2013;15(4):465-76.

20. Lee SE, Lee H-Y, Cho H-J, Choe W-S, Kim H, Choi JO, Jeon E-S, Kim M-S, Kim $J-J$, Hwang K-K. Clinical characteristics and outcome of acute heart failure in Korea: results from the Korean acute heart failure registry (KorAHF). Korean Circ J. 2017:47(3):341-53.

21. Gebremariam S, Moges T. Pediatric heart failure, lagging, and sagging of care in low income settings: a hospital based review of cases in Ethiopia. Cardiol Res Pract. 2016;2016:7147234

22. Abdissa SG, Oli K, Feleke Y, Goshu DY, Begna DM, Tafese A. Spectrum of cardiovascular diseases among Ethiopian patients at Tikur Anbessa Specialized University teaching Hospital, Addis Ababa. Ethiop Med J. 2014; 52(1):9-17.

23. Sliwa K, Carrington M, Mayosi BM, Zigiriadis E, Mvungi R, Stewart S. Incidence and characteristics of newly diagnosed rheumatic heart disease in urban African adults: insights from the heart of Soweto study. Eur Heart J. 2009;31(6):719-27.

24. Gattis WA, Hasselblad V, Whellan DJ, O'connor CM. Reduction in heart failure events by the addition of a clinical pharmacist to the heart failure management team: results of the pharmacist in heart failure assessment recommendation and monitoring (PHARM) study. Arch Intern Med. 1999; 159(16):1939-45.

25. Khatibzadeh S, Farzadfar F, Oliver J, Ezzati M, Moran A. Worldwide risk factors for heart failure: a systematic review and pooled analysis. Int J Cardiol. 2013;168(2):1186-94.

26. Habte B, Alemseged F, Tesfaye D. The pattern of cardiac diseases at the cardiac clinic of Jimma University specialised hospital, south West Ethiopia. Ethiop J Health Sci. 2010;20(2):99-105.

27. Mayosi BM. Contemporary trends in the epidemiology and management of cardiomyopathy and pericarditis in sub-Saharan Africa. Heart. 2007:93(10): 1176-83.

28. Sliwa K, Damasceno A, Mayosi BM. Epidemiology and etiology of cardiomyopathy in Africa. Circulation. 2005;112(23):3577-83.

29. Agbor VN, Essouma M, Ntusi NA, Nyaga UF, Bigna JJ, Noubiap JJ. Heart failure in sub-Saharan Africa: a contemporaneous systematic review and meta-analysis. Int J Cardiol. 2018;257:207-15.

30. Hummel A, Empen K, Dörr M, Felix SB. De novo acute heart failure and acutely decompensated chronic heart failure. Dtsch Arztebl Int. 2015; 112(17):298-310.

31. Yancy CW, Jessup M, Bozkurt B, Butler J, Casey DE, Colvin MM, Drazner MH, Filippatos GS, Fonarow GC, Givertz MM. 2017 ACC/AHA/ HFSA focused update of the 2013 ACCF/AHA guideline for the management of heart failure: a report of the American College of Cardiology/American Heart Association task force on clinical practice guidelines and the Heart Failure Society of America. Circulation. 2017; 136(6):e137-61.

32. Callender T, Woodward M, Roth G, Farzadfar F, Lemarie J-C, Gicquel S, Atherton J, Rahimzadeh S, Ghaziani M, Shaikh M. Heart failure care in lowand middle-income countries: a systematic review and meta-analysis. PLoS Med. 2014;11(8):e1001699.

33. Dokainish H, Teo K, Zhu J, Roy A, AlHabib KF, ElSayed A, Palileo-Villaneuva L, Lopez-Jaramillo P, Karaye K, Yusoff K. Global mortality variations in patients with heart failure: results from the international congestive heart failure (INTER-CHF) prospective cohort study. Lancet Glob Health. 2017;5:e665-72.

34. Cooper HA, Dries DL, Davis C, Shen YL, Domanski MJ. Diuretics and risk of arrhythmic death in patients with left ventricular dysfunction. Circulation. 1999;100(12):1311-5.

35. Lowe BS, Therrien J, Ionescu-Ittu R, Pilote L, Martucci G, Marelli AJ. Diagnosis of pulmonary hypertension in the congenital heart disease adult population. J Am Coll Cardiol. 2011;58(5):538-46.

36. Ventetuolo CE, Klinger JR. Management of acute right ventricular failure in the intensive care unit. Ann Am Thorac Soc. 2014;11(5):811-22.

37. Mohammed SF, Borlaug BA, Roger VL, Mirzoyev SA, Rodeheffer RJ, Chirinos JA, Redfield MM. Comorbidity and ventricular and vascular structure and function in heart failure with preserved ejection fraction: a community based study. Circ Heart Fail. 2012;5:710-9 CIRCHEARTFAILURE. 112.968594

38. Campbell RT, Jhund PS, Castagno D, Hawkins NM, Petrie MC, McMurray JJ. What have we learned about patients with heart failure and preserved 
ejection fraction from DIG-PEF, CHARM-preserved, and I-PRESERVE? J Am Coll Cardiol. 2012;60(23):2349-56.

39. Collins SP, Pang PS, Lindsell CJ, Kyriacou DN, Storrow AB, Hollander JE, Douglas Kirk J, Miller CD, Nowak R, Frank Peacock W. International variations in the clinical, diagnostic, and treatment characteristics of emergency department patients with acute heart failure syndromes. Eur J Heart Fail. 2010;12(11):1253-60

\section{Publisher's Note}

Springer Nature remains neutral with regard to jurisdictional claims in published maps and institutional affiliations.

Ready to submit your research? Choose BMC and benefit from:

- fast, convenient online submission

- thorough peer review by experienced researchers in your field

- rapid publication on acceptance

- support for research data, including large and complex data types

- gold Open Access which fosters wider collaboration and increased citations

- maximum visibility for your research: over $100 \mathrm{M}$ website views per year

At $B M C$, research is always in progress.

Learn more biomedcentral.com/submissions 